\title{
From Socrates to Satellites: iPad Learning in an Undergraduate Course
}

\author{
Jodie Wakefield, Dennie Smith \\ Department of Teaching, Learning and Culture, Texas A\&M University, College Station, USA \\ Email: jodiem@cehd.tamu.edu, denniesmith@tamu.edu
}

Received July $10^{\text {th }}, 2012$; revised August $12^{\text {th }}, 2012$; accepted August $28^{\text {th }}, 2012$

\begin{abstract}
Finding, evaluating and using information are necessary skills for the $21^{\text {st }}$ century college student to engage in critical thinking and problem-solving. This qualitative study was conducted during the fall of 2011 at a major research institution in an undergraduate face-to-face course entitled Multicultural Education. Professors designed a course to practice these skills outside and inside the classroom. Students were randomly assigned to the problem-solving class (17) and the traditional class (18) studying multicultural education for teacher education. The iPads were issued to the students in August of 2011 to be used not only in the Multicultural Education course, but students were also encouraged to use the devices in all of their courses throughout the fall and spring semesters. Students were expected to watch videos, read assignments and complete other course assignments before coming to class to engage in problem-solving using their iPads. This paper presents observational and survey data related to students and professor engaging in problem-solving activities.
\end{abstract}

Keywords: iPad; Problem-Solving; Mobile Learning; Undergraduate; Technology

\section{Introduction}

With such dependence on mobile technology in all aspects of our lives, it is difficult to imagine that educators would not fully embrace and incorporate these devices into learning environments, especially given the implications for student learning and teacher training. Apple Inc.'s recent announcement that they will "offer a series of software tools to make it possible to move education from textbooks to interactive digital lessons-easily prepared by publishers, teachers or others interested in creating learning materials" suggests the direction resources in education will take: digital and interactive (Potter, 2012).

Rapidly-evolving mobile technology has created opportunities and challenges for teachers and students. With the advent of iPads and other mobile devices came the ability to find, evaluate, and use information nearly instantaneously at any time and place. However, very little research has been reported in professional journals that describes ways in which educators can integrate the technology into teaching and learning in order to capitalize on the opportunities or overcome the challenges they will likely encounter as they move to integrate mobile devices into university coursework. According to Pachler, Bachmair, and Cook (2010), without any comprehensive theoretical and conceptual framework to explain the complex interrelationship between the characteristics of rapid and sometimes groundbreaking technological developments, it is difficult for educators to determine how and why this type of technology should be used in the classroom. This paper explicates the importance of mobile technology integration at the university level and also provides a deeper understanding of the advantages and tensions of this emerging technology on teaching and learning.

In the fall of 2011, one of the researchers provided students with the opportunity to transition from a traditional to a mobile learning classroom experience. Rather than the traditional delivery method of textbooks and lectures, students were provided with iPads, a mobile device through which they were able to enhance their problem-solving, evaluative, analysis, and synthesis skills. A case study approach was used to document the professor's and students' experiences related to the dramatic change in their instructional approaches using this technology (Hofer \& Swan 2006). All of the learning materials for this course were accessible through the iPad. Websites along with PDF files were used to access major journal articles used for learning.

\section{Review of Literature}

Education is in a transitional period. Educators are shifting from paper-based classrooms to technology-integrated classrooms because of the needs of the $21^{\text {st }}$ century learner and educator (Haythornthwaite \& Andrews, 2011). With educators having the ability to electronically access textbooks, email, blackboard learning systems, Google, and other evolving systems, it appears that the nature of teaching and learning will be forever changed and transformed with new pedagogy. Indeed, educators are now dependent on the same devices as their students and expect their students to continuously access these devices for instructional purposes.

Recently, several universities have reported a variety of implementations and/or research related specifically to the use of iPads by professors and/or students. Several of these findings included: students using an annotation of text application on the iPad scored $25 \%$ higher on questions involving transferring learning; the iPad increased student engagement in learning; students expected to use the e-reader function with $75 \%$ agreeing that the iPad enhanced their learning; and, the iPad was somewhat distracting in large classes (Staff Writers, 2012). 


\section{Developing a Framework}

A framework for the study of mobile learning was adapted from Sharples, Taylor, and Vavoula (2005) who proposed research based on the following questions as criteria:

1) Is it significantly different from current theories of classroom learning?

2) Does it account for the mobility of learners?

3) Does it cover both formal and informal learning?

4) Does it theorize learning as a constructive and social process?

Why as educators should we be interested in the idea of mobile technology integration, and what makes it different from other types of technology integration? In this paper, mobile learning is defined as the ability to learn anywhere at any time mediated by mobile devices, such as iPads (Traxler, 2009). Evolving research has identified several opportunities and advantages allotted through mobile learning devices such as:

1) Improving social interaction (Pachler et al., 2010);

2) Encouraging collaborative learning (George \& Serna, 2010);

3) Enabling personalized learning (Pachler et al., 2010);

4) Other evolving and important areas of research including learning in and out of classrooms, allowing for individualization of instruction and meaningful learning.

Consistent with the advances in technology are the changes in teaching and learning across the entire educational spectrum, from early childhood to adulthood. With students having access to more and more complex technologies when they enter college, the very nature of being a student is changing. Students expect to be able to access the world with their fingertips and to find information as quickly as possible. Thus, the days of the paper and pencil classroom are coming to an end, and the nature of teaching and learning is transitioning formally and informally to virtual resources. According to Murray and Olcese (2011), the $21^{\text {st }}$ century student will need technology skills to be motivated and competitive in the future as well as able to collaborate in ways that take advantage of the iPad hardware and operating system capabilities in order to support 21st century skills. The shift from learning information in schools to finding and evaluating information independently will help prepare learners for an ever-changing future.

It is not only the learners who expect change, but teachers as well. Teacher capabilities are changing and they are becoming increasingly reliant on technology in organizing and delivering relevant instruction. Teachers at all levels use the Internet daily to enhance their instruction. Because of this, the expectations placed on teachers for technology integration have greatly increased. However, many teacher preparation programs have not adequately embraced the incorporation of technology in training programs, and in many instances, are struggling to keep up with the pace of advancing technologies (Morrison \& Jeffs, 2005; Lee \& Hollebrands, 2008).

Although technology allows access to important materials, supports collaborative learning environments, and allows for differentiated instruction, it is does not come without its disadvantages and tensions. This is a problem because mobile technology integration is no longer a question of if we should but how we should. Twenty-first century learners easily adapt to constantly evolving technology. Rosen, Carrier, \& Cheever (2010) posit that teachers should work towards meaningful incorporation of technology in an educational setting to ensure that their students are engaged in the learning process. Teachers should not question the validity of mobile technology because mobile devices are ubiquitous and a part of their students' daily lives. Rather, according to Rosen et al. (2010), teachers should ask: how can we successfully incorporate technology into the learning environment?

Teacher preparation programs face the challenge of preparing teachers to implement mobile technology in their classrooms. If teachers are expected to utilize these new types of technologies, they must learn how to do so during their teacher preparation programs. Almost a decade ago, Young and Bush (2004) noted, "in order to cultivate the kind of technology literacy in our students called for by leaders in the field, it must simultaneously be cultivated in our teachers" (p. 1). With rapidly changing mobile technology, how is it possible to adequately prepare teachers to use new technologies? How do school districts, universities and educators find the appropriate balance between mobile learning and the traditional, effective classroom experience?

\section{Applying Mobile Learning in an Undergraduate Classroom}

\section{Context for the Study}

An opportunity emerged to explore the possibilities and impact of mobile learning through the rapid development of the iPad. This study was conducted during the fall of 2011 at a major research institution in an undergraduate face-to-face course entitled Multicultural Education. An Institutional Review Board Proposal was approved for this study. One of the researchers taught a section in which the students were provided with iPads to use throughout the semester in and out of class. The iPads were issued to the students in August to be used not only in the Multicultural Education course, but students were also encouraged to use the devices in all of their courses throughout the fall and spring semesters. The population consisted of 17 undergraduate students studying teacher education. The goals of Multicultural Education were to develop and increase student background knowledge of multiculturalism and education and to provide insights into the cultural, historical, and philosophical foundations of education in a multicultural society.

\section{Data Collection and Analysis}

For this research, we used a case study approach (Hofer \& Swan, 2006). This approach allowed us to closely examine the use of the iPads, the professor's and students' perceptions and their interactions with each other. The professor and his students were informally interviewed and observed during class throughout the semester and formal interviews were conducted with three students at the conclusion of the course. In addition, lesson plans, surveys, and student artifacts were collected and analyzed.

Because future teachers will be expected to implement the same type or different technology in their own classrooms, we desired a deeper understanding of how mobile devices can be effectively integrated into a teacher preparation course by both the professor and students. All students used the same technology; therefore, everyone had the same opportunities and advantages for learning and accessing resources. We also wanted to understand how an instructor approached this type of learning environment and what motivated the professor to create a mobile technology-integrated classroom. 
New questions evolved during this study related to how students interacted with one another while the iPads were being used. Did the students prefer this technology-integrated course to their other courses? What challenges did they face throughout the semester? Did they perceive the professor and the course to be a successful and meaningful experience? These questions were answered through interviews and an end-ofcourse survey.

\section{Expectations for Technology Integration}

As mobile learning is learning anywhere at any time, the iPads served as a tool to facilitate learning in a face-to-face and virtual context. The course was organized in the Blackboard Learning Management System (Blackboard, Inc. (n.d)) with each week's assignments referencing internet resources including articles, videos, and other interactive materials. The professor expected that the iPads would be used in and out of class as a tool to find, evaluate, and use information related to critical topics. He wanted to create a learning environment in which his students were challenged to search for information on the Internet, critically decide if the information was valuable, and when and if it should be applied to topics and issues relative to course objectives. The students also used the iPads to watch videos and conduct searches relevant to the experiential learning activities (i.e., simulations of real world scenarios, debates, and group projects).

The students were not instructed in how to use the iPads with various applications or functionality. Rather, they were encouraged to explore the possibilities of using the iPads with various assignments related to making videos, photographs, finding virtual artifacts, collaborations, and communications. Students collaborated and shared ideas about various applications and the use of the iPads in a natural and non-competitive atmosphere.

The major goal of the iPad implementation was to shift from the traditional teacher-centered environment to the studentcentered collaboration model for learning. A key component of this study included the professor's desire to create and explore an all-inclusive classroom: teacher + student + technology. One of the observed characteristics of this class was that students could use their iPads at any time during the class to access information and to communicate with each other and the professor.

This experimental class was remarkably different from other sections of this course as well as all other teacher education courses offered during the fall semester: no paper, handouts, or direct lecture. Rather than teaching through the teacher-up-front model, the professor served primarily as a facilitator. He guided students as to what they should learn, how they should learn it, how they should apply it, and how he would assess them. Mobile devices appeared to inherently lend themselves to this type of learning environment as they encouraged the utilization of all electronic materials and problem-solving skills. The iPads also allowed for student mobility and a wider range of collaborations: students were constantly moving about and sharing with others within the classroom itself, and they were also able to learn and access course materials outside of class and to share access to resources with classmates through email, Twitter, and face-to-face iPad application. Formal and informal learning also occurred: students were provided with pertinent information through Blackboard Management System on mul- ticultural education and provided with class time to engage in collaborative group activities in learning major concepts. These constructivist activities, facilitated by the iPads, "enabled immersive experiences" (Traxler, 2009: p. 8).

Some similarities did remain between traditional classrooms and the new mobile learning classroom. The similarities included formal and informal assessments, specific content, problem-solving teaching methodology, and the presence of the teacher. The content does not necessarily change when technology is used, but rather the delivery and learning methodologies change. Another similarity was the presence of the teacher in a technology-implemented classroom. Technology appeared to change the role of the teacher to include more facilitation and coaching during learning, but the teacher still played an important role. The professor encouraged his students to maintain the balance between mobile technology implementation and traditional teaching methods by including activities that utilized the iPads and activities that did not.

\section{Findings and Analysis}

We conducted three classroom observations during the semester each lasting 75 minutes documenting the professor's and students' behaviors. Additionally, we conducted biweekly interviews with the professor who referenced journal notes during the process. At the conclusion of the semester, we conducted extended interviews with three students and reviewed comments on the final course evaluations. Our findings demonstrated similar comments from the observations, interviews, and written comments and provide evidence of consistency of the findings. In this section, we explore the results of the classroom observations as well as how the instructor and his students perceived the implementation of the iPads.

\section{Observations}

During the observations, we found that all of the students had their iPads out before, during, and after class. Students explored new apps or did last minute preparation for the class. In addition, students used their iPads when the professor asked them to define unfamiliar topics and search for court cases and examples that supported their class discussions and debates. After finding examples independently, they would then share their findings with each other and eventually share their results with the entire class. Throughout the semester, it was apparent that the iPads and the professor supported a collaborative learning environment. Consequently, the students appeared to be comfortable using their mobile devices in this manner.

The professor projected his iPad onto a large screen to review students' article postings and reflections. He also used various applications throughout the class to convey aspects of a lesson and to introduce students to the functionality of the iPad. He continuously encouraged his students to use their iPads throughout all aspects of the class for problem-solving. Because of the iPad integration, the students could find, evaluate and use information for problem-solving during class. The instructor facilitated experiential learning with assignments that were enhanced with access to the iPads. One of the assignments required students to conduct a video interview of a person from another culture and show it in class. These experiences created a learning in-context classroom for students to apply knowledge to their activities and clarify concepts they did not understand. 
Interestingly, the students appeared more comfortable and confident in verbally participating and sharing their ideas with the class when they had access to their iPads. During one observation, the students were asked to put up their iPads as the professor wanted everyone's attention up-front. After playing music and lyrics related to topics being discussed, he asked students to answer his questions related to the presentation. The students seemed hesitant at first. It appeared that when they could not access their iPads to support their answers, they were less willing to be active participants. One student stated, "I became increasingly reliant on the iPad to answer questions in class.” This reinforced the idea of a new breed of student who increasingly relies on instantaneous access to technology.

\section{Interviews}

\section{Professor}

We interviewed the professor of the course during biweekly interviews each lasting approximately 60 minutes. Table 1 displays the questions we asked during the professor interviews.

The professor of this Multicultural Education course was determined to successfully integrate the iPad technology into the classroom. When asked what his goals were for this course, he stated: "I want to see everyone working with the technology at the same time." In August, he provided the 17 students with their own iPads. He passed them out with the disclaimer that the students would need to return the iPads at the conclusion of the spring 2012 semester. He was excited by such student comments as, "I can't believe we have to give these up... we will want to keep them!” and "I never thought I would enjoy coming to an eight o'clock class!”

The professor's expectations for his students included: students would access the iPads both in and outside of the classroom; students would be responsible for readings and watching educational videos outside of class so that they would be prepared to discuss, participate, and problem-solve during class.

In the early stages of the semester, the professor noted that he found himself going through an adjustment period. Multiple students approached him with the concern, "Are we meeting your expectations?" He stated that the students appeared to be uncomfortable with this problem-solving model as they frequently questioned what his expectations were for them. In addition, throughout the semester, he experienced unexpected complexities of integrating the iPads. At times the students became distracted by the devices, leading to the professor's occasional request that the devices be put away. He discovered that the balance in this transitional classroom was to allow the students to struggle in order to increase their problem-solving abilities. Students collaborated freely with other students to

Table 1.

Professor interview questions.

\footnotetext{
- How did you use the technology in class?

- What challenges did you experience in this type of setting?

- What were your goals for your students using the iPad to find, evaluate and use information in class?

- Do you think the iPad is beneficial to a collaborative group environment?

- How do you think your students' problem-solving skills were impacted by the iPads?

- What affect did the use of technology have on you as the instructor?
}

complete their assignments. At the same time, he acknowledged that students needed more feedback from him and more specific instructions as they relied on him as the facilitator.

\section{Student Interviews}

Table 2 demonstrates the questions we asked the students during the extended interviews. We interviewed three randomly selected students from the class, and each interview lasted approximately 30 - 45 minutes.

In the extended interview with "Marcy," we were provided with insights from one of the students. Marcy was a 19 year old undergraduate student who desired to eventually teach at the early childhood level. She was positive about the class experience and believed that iPad technology allowed many expanded learning opportunities for students and teachers. Marcy stated that "The iPad allowed me to connect to the world, family, friends, and classmates during the fall semester. If we had not had an iPad, we would not have been able to have these unique learning experiences." Marcy stated that one of the biggest advantages of every student having his/her own iPad during the semester was that it created an equal playing field: "Because we all were given the same technology, we were all able to experience things at the same time. We all looked up information together." All students had access to the same information at the same time. Rather than one or two students having an iPad and the rest having laptops or paper and pen, all students were granted equitable learning opportunities. Marcy also stated that the environment the professor created with the iPads was challenging but built on her problem-solving skills. "When I was in high school, I never had to think for myself. My teachers would answer any questions I had. [The professor] didn't do this. He made us think for ourselves" and find the answers to our questions with research through a variety of resources. Marcy hoped that she would have another opportunity like the one she was given in the fall 2011 semester. She thought it was important that more teachers and professors incorporate technology into their classrooms. Marcy believed that this was where the classroom was headed: completely paperless and completely mobile.

"Elaine," also 19 and an early childhood major, stated that the iPads exposed her and her classmates to controversial real world problems. By accessing information on unfamiliar concepts and stepping out of her comfort zone, Elaine was able to increase her problem-solving skills during this class. When asked about the professor's expectations for the course and for iPad integration, Elaine stated that the professor "had really high expectations for us. We were able to live up to his expectations, though." Elaine also noted that the professor created a class that was unique: "He doesn't just lecture and give us PowerPoint slides.” Rather, the class was interactive, experien-

Table 2.

Student interview questions.

- How did you use the technology in class?

- What challenges did you experience in this type of setting?

- How did you use the iPad to find, evaluate and use information in class?

- Do you think the iPad is beneficial to a collaborative group environment?

- How do you think your problem-solving skills were impacted by the iPads?

- What affect did the use of technology have on the instructor? 
tial and interesting to Elaine and her peers. They were able to engage in in-depth discussions because they could all access information on their iPads. For Elaine, there was never a boring moment in this seemingly unstructured course. She stated that she was able to take the problem-solving skills (and iPad) and synthesize them into her other courses to clarify unfamiliar concepts.

"John," a 19 year old student and a future teacher, also experienced the positive effects of this iPad classroom. Although he and his classmates struggled a bit with a less structured class and unclear expectations, they succeeded in becoming better problem-solvers because the professor did not provide them with explicit answers. He stated, "We used our iPads to research topics, analyze information about that topic, and then use what we learned in our group videos and writing assignments." John understood that the professor was trying to do something new and unique with the iPads. John called this classroom a "powerful idea... and a liberating experience." He said he discovered the following through the use of these mobile devices:

1) iPads are tools with which learning is enhanced.

2) The iPads allowed students to be confident in sharing their ideas without being judged by others.

3) iPads created a community of learners.

John used his iPad outside of class to find information, search the Web, and communicate with his classmates using Facetime. Just as Elaine did, John indicated he was able to transfer skills from this class to his other courses.

\section{Tensions}

Reliance on the use of iPads as a primary teaching and learning tool created some tensions for both the instructor and the students at times throughout the course. Although this was an innovative classroom in which technology was integrated, the students still heavily relied on the instructor for feedback. In addition, neither the students nor instructor knew exactly what to expect in a technology-implemented course.

Marcy, Elaine, and John all provided descriptions of the tensions they experienced during the course. They all admitted that the iPads could be a distraction when being used in class (like cell phones can be), but as long as the instructor set expectations for when and how they should be used and was observant of how his students were using the iPads, the devices did not take away from the class. John stated that if students have the "discipline to be professional in class," then the iPads did not detract from learning. The students also agreed that the iPads enhanced their problem-solving skills, but at the same time, created some discomfort. Students were required to solve problems on their own with the help of iPads, something that was unfamiliar to many of the students. They were encouraged not to rely on the professor to provide answers that they themselves could answer if they searched for it online. Marcy, a self-proclaimed "expert problem-solver," said that this was uncomfortable for her and her classmates because their high school teachers had never required as much independence from them. Elaine felt that throughout the semester, all of the students increasingly relied on their iPads, so when they were not being used, the class did not seem as engaging. John also stated that even though the expectation for cumulative group activities was to use the iPads to present their projects, some students resisted using the iPads. In general, however, most of the students ap- peared to enjoy the positive learning environment created by the professor and were able to work through their discomforts quickly.

The experiment in transitioning to mobile learning indicates that this type of environment is a "change" for everyone, and neither instructor nor students completely understood the implications of integrating technology at this level. This again demonstrated the importance of continuing to conduct largescale mobile learning research to determine how mobile devices could be best incorporated into teacher preparation programs. In addition, there is a need for deeper understanding of the most successful ways to implement this technology into university classrooms.

\section{Conclusion}

The final examination for this course captured many of the innovative aspects of the class and highlighted some of the more significant attributes of integrating technology into the college classroom. Students had to identify a strategy to convince a school and community of the importance of incorporating more diversity in the curriculum. The question required them to generate at least three alternatives and select the best response with supportive reasoning. Students were given this problem three weeks before it was due. They continued to raise questions during class meetings about the professor's expectations for the respective responses and were reluctant to rely on their ability to complete the assignment without specific criteria for how to achieve an A grade. The professor noted that the ambiguity was purposeful in creating and stimulating problem-solving in order for the students to use their iPads to fully explore possible answers. Students collaborated with each other and explored a multitude of possibilities in the interim. According to the professor, due to the high level of collaboration, students' demonstrated a deeper understanding of multiculturalism in their final course assignment as evidenced by their examples noting the importance of multiple viewpoints and positive contributions of people from diverse backgrounds. Most importantly, their communication through the use of their iPads exposed them to a number of solutions and critical evaluations for this problem. He believed that compared to previous classes, the students demonstrated more systematic skills in their approaches to problem-solving, collaborative learning, and finding critical information on the Internet.

The end of semester Personalized Instructor/Course Appraisal System (PICA) survey allowed anonymous insights into the students' perceptions of this course. The results of the PICA were made available after course grades were posted in the registrar's office as per university policy. The students rated this course and the instructor highly. Of the 16 students who completed the survey, 87.5\% "strongly agreed" that they "had the opportunity to engage in new learning experiences in this class." Expanded comments for this section included: "Yes! We got to use iPads throughout the course;" "Lots of new ways of learning;" "We were given iPads and that was a new learning experience that I really enjoyed and did a lot of things with that device.” Regarding, teacher effectiveness, $75 \%$ of students "strongly agreed" that the professor was effective. In the open-ended portion of this survey question, students provided the following statements: "[The professor] encouraged discussion and the students' learning from one another and to be independent from the teacher, so we had to figure out a lot of 
things on our own. He didn't just hand us the information;" "I learned a lot about expanding my way of thinking and creativity. Different points of view were very mind opening;" and, "[The professor] was wonderful! His class was very engaging." The survey statement "my learning was enhanced by the use of educational materials in this course (i.e., textbooks, media, handouts, films, Webboard, technology, and PowerPoint) indicated that $68.8 \%$ of the 16 participants "strongly agreed." The open-ended comments included: "We used iPads which helped so much! Instead of pulling out a huge laptop;" "iPads! The use of new technologies was very useful in learning new things very quickly and accessing new information that is not widely available in a normal lecture style class;" "The iPad given to us at the beginning of the year has really increased my interest in this class. I found myself wanting to complete assignments with ease. I had a blast taking this course;" and, "As we had iPads, each of us had the opportunity to find information on the Web and shared it with the class." Only $37.5 \%$ "strongly agreed" that they received timely and informative feedback on the course assessments. One student stated, "Sometimes very confused about dates and expectations." This supports the observations and interviews that suggested the students were uncomfortable with the lack of constant and instantaneous feedback.

The goals of this Multicultural Education course (increase student background knowledge of multiculturalism and education, and to provide insights into the cultural, historical, and philosophical foundations of education in a multicultural society) were achieved through the utilization of the iPads. The professor was able to successfully implement the iPads into a university level course. Instead of the traditional paper-based classroom, this transitional classroom was paperless, focused on problem-solving, and emphasized teacher and student collaboration rather than the all-knowing professor. Because of the positive and collaborative environment that the professor created, the students responded positively and acknowledged this course as meaningful, engaging, and challenging.

\section{Implications}

The solutions to the challenges of mobile technology integration into all levels of classroom teaching and learning are complex. The one definite is that mobile technology is ubiquitous and will continue to change both teachers and learners as it is implemented in classrooms. Meeting the challenges will require more large-scale research to determine the effects of mobile learning on student outcomes. This will allow educators insight into how exactly technology should be used which will affect what technology will be purchased by school districts and universities and in what quantity. The face of research might also need a facelift. Mobile learning research must be more readily available for educators so that they know the best uses of mobile devices, and teachers and students must become better problem-solvers as the applications to educational learning rapidly multiply and change. Universities must also make the commitment to technology integration and must keep it on a level playing field so that all teachers and students are provided with equal teaching and learning opportunities.

With each technological innovation are questions about if it is better than what was previously used or currently exists and how we as educators should integrate each new innovation into the classroom (Vratulis, Clarke, Hoban, \& Erickson, 2012).
Historically, educators have relied on research-based instruction to guide the direction of learning. However, with everevolving technology, it is difficult to rely on the slower accumulation of research. Educators must become experiential researchers who constantly search for answers, evolve their instruction and become adaptable to the constantly evolving mobile technology. The idea of mobile learning and the ability to equalize learning experiences have significant implications for the future of teaching and learning. If the adage, "teachers teach the way they've been taught" has any traction in teacher preparation programs, then more research related to mobile learning will facilitate the advancement of using technology in teaching and learning. As the study demonstrated, there are multiple points of "tension" for both teachers and learners as educators navigate the changes from Socrates to satellites.

\section{REFERENCES}

Blackboard, Inc. (n.d.). URL (last checked 12 March 2012). http://www.blackboard.com/us/index.aspx.

George, S., \& Serna, A. (2010). Introducing mobility in serious games: Enhancing situated and collaborative learning. In J. Jacko (Ed.), Human-computer interaction: Users and applications. New York: Springer Science and Business Media.

Haythornthwaite, C., \& Andrews, R. (2011). E-learning theory and practice. London: Sage.

Hofer, M., \& Swan, K. (2006). Technological pedagogical content knowledge in action: A case study of a middle school digitial documentary project. Journal of Research on Technology in Education, 41, 179-200.

Lee, H., \& Hollebrands, K. (2008). Preparing to teach mathematics with technology: An integrated approach to developing technological pedagogical content knowledge. Contemporary Issues in Technology and Teacher Education, 8. http://www.citejournal.org/vol8/iss4/mathematics/article1.cfm

Morrison, F., \& Jeffs, T. (2005). Outcomes of preservice teacher's technology use. Assistive Technology Outcomes and Benefits, 2, 1-8.

Murray, O., \& Olcese, N. (2011). Teaching and learning with iPads, ready or not? TechTrends, 55, 42-48. doi:10.1007/s11528-011-0540-6

Pachler, N., Bachmair, B., \& Cook, J. (2010). Mobile learning: Structures, agency, practices. New York: Springer Science and Business Media.

Potter, N. (2012). Apple to remake textbooks, inspired by Steve Jobs. $a b c N E W S$. URL (last checked 20 January 2012).

http://abcnews.go.com/blogs/technology/2012/01/apple-to-remake-te xtbooks-project-begun-by-steve-jobs/

Rosen, L., Carrier, L., \& Cheever, N. (2010). An explosion of WMDs: Wireless mobile devices. Rewired: Understanding the iGeneration and the way they learn. New York: Palgrave Macmillan.

Sharples, M., Taylor, J., \& Vavoula, G. (2005). Towards a theory of mobile learning. Birmingham: University of Birmingham.

Staff Writers (2012). 18 enlightening iPad experiments in education [Web log post]. URL (last checked 8 February 2012).

http://www.onlineuniversities.com/18-enlighteni-ipad-experiments-i n-education

Traxler, J. (2009). The evolution of mobile learning. In R. Guy (Ed.), The evolution of mobile teaching and learning (pp. 1-14). Santa Rosa, CA: Informing Science Press.

Vratulis, V., Clarke, T., Hoban, G., \& Erickson, G. (2012). Additive and disruptive pedagogies: The use of slowmation as an example of digital technology integration. Teaching and Teacher Education, 27, 1179-1188. doi:10.1016/j.tate.2011.06.004

Young, C., \& Bush, J. (2004). Teaching the English language arts with technology: A critical approach and pedagogical framework. Contemporary Issues in Technology and Teacher Education, 4, 1-22. 